\title{
The Influence of Words Categories on Translating Postgraduate Abstracts in the Field of Evaluation and Measurement at Mu'tah University
}

\author{
Eissa Al Khotaba (Corresponding author) \\ Dept. of English Language and Literature, Mu'tah University, P.O. Box: 7, Mu'tah, Al Karak, Jordan \\ E-mail: alkhotabaeissa@yahoo.com \\ Bassam Al Magarbeh \\ Dept. of English Language and Literature, Mu'tah University, P.O. Box: 7, Mu'tah, Al Karak, Jordan
}

Doi:10.7575/aiac.alls.v.6n.2p.17

URL: http://dx.doi.org/10.7575/aiac.alls.v.6n.2p.17
Received: $15 / 11 / 2014$

Accepted: 20/01/2015

\begin{abstract}
The goal of this study is to investigate the influence of words categories on translating postgraduate students abstracts doing their M.A in Evaluation and Measurement at Mutah university in Jordan for the academic year 2014/2015. This qualitative and quantitative study includes 15 postgraduate students' abstracts in the field of Evaluation Measurement. The sample of the study was selected randomly. The researcher used two research instruments; textual analysis and interviews. The findings of this research indicated those words' categories play a significant role in achieving the correct meaning and selecting an appropriate translation equivalent. This study recommends that enough attention should be provided by translators when translating words' categories in postgraduate abstracts especially in areas such as evaluation and measurement. Also, this study recommends that further future research be conducted in this area to overcome problems in English as a foreign translation, particularly in contexts such as Jordan.
\end{abstract}

Keywords: Words Categories, Evaluation Measurement, Translating, Postgraduate, Abstract

\section{Introduction}

During the last few decades much research on translation emerged recording an outstanding outcome in the field of translation studies not only in English as a second language, but also in English as a foreign language. As a result, the 20th century has become to be known as the age of translation or reproduction and it was the most common way to communicate between different levels such as philosophy and science in order to make a balanced meaning in their knowledge (Jumpelt, 1961). Translation as an area of interest has been defined differently by many scholars in which it is commonly known as the process of conveying meaning in forms of oral or written text from the source language (SL) to the target language (TL) conducted by translator in a specific socio-cultural context (Benjamin, 1923). Similarly, Bell (1991) attempted to arrange the translation process and set it within a systemic form of language. He divided it into three parts, namely model, meaning and memory as well as, assessing how logical relationships are organized and mapped onto the syntactic systems of a language .

Baker (1992) conducted a study to explain the various areas of language ranging from the meaning of single words and expressions to grammatical categories according to cultural contexts that existed in linguistics theory. Her work starts at the simple level and grows in complexity by widening its focus gradually. The findings of her research demonstrated that there is a strong relationship between words and their categories in translation field. Miller (1990) in his work an on-line lexical database focused on the translation process, justifying that meaningful sentences are composed of meaningful words. He states that any system that hopes to process natural languages as people must have information about words and their meanings.

This information is traditionally provided through dictionaries, and machine-readable dictionaries that are now widely available. But dictionary entries evolved for the convenience of human readers, not for machines. He adds, WorldNet provides a more effective combination of traditional lexicographic information and modern computing. WorldNet is an online lexical database designed for use under program control. English nouns, verbs, adjectives, and adverbs are organized into sets of synonyms, each representing a lexicalized concept. Semantic relations link the synonym.

Like many other developing countries, English is taught in Jordan a foreign language where linguists and translators are very much concerned with improving the field and profession of translation (Khanfar, 2013). More particularly, educationist and linguistics are interested in investigating problems that translators and students face in the translation process. They show that translation is an issue for most of the translators working in the areas (Al Sohbani and Muthanna, 2012). As a result, the researcher felt the necessity for conducting this kind of research to reach a conclusion concerning problems of translation that encounter translators when working with words categories while translation postgraduate abstract in the field of evaluation and measurement. 
English is taught in Jordan as an EFL. Researchers in the area of English language teaching and translation in Jordan indicate that students face many difficulties in translation (Khanfar, 2013). They state that most of these difficulties may relate to context, equivalent, cultural or linguistic elements. Al Sohbani and Muthanna (2012) translators encounter a problem when attempting to translate words' categories in postgraduate abstracts produced by M.A students majoring in Evaluation and Measurement. As a result, this research is an attempt to explore the influence of words' categories on translating postgraduate abstracts in the field of evaluation and measurement at Mu'tah University in Jordan.

\section{Research Objectives}

This research intends to achieve the following research objectives:

i. To examine the effect of words' categories on translating postgraduate abstracts in Evaluation and Measurement field. ii. To help translators achieve translatability of words' categories .

\section{Research Questions}

This study addresses the following research questions :

Q1: To what extent do words' categories affect translating postgraduate abstracts in Evaluation and Measurement field? Q2: How can translators translatability of words categories?

\section{Literature Review}

Many studies have been conducted to investigate the effect of words categories on translation and how this factor affects or hinders translation process. Hussein Abdul-Fattah (2010-2012) conducted a research to assess of the proficiency of advanced university students in the area of English lexical collocations as manifested in their translation from Arabic into English. The sample of his study consists of nine M.A students majoring in translation were subjected to thorough scrutiny of deviant collocational clusters in their written performance. The findings of his research indicated that ushered into the need to concentrate, formally and explicitly, on lexical learning in general, and collocations in particular, at all levels.

Moharram (2004) conducted a study on student's errors while translating Arabic into English and found a considerable number of errors attributed to the inappropriate use of vocabulary, prepositions and gender; meaningless use of words categories; incorrect use of grammatical forms; use of long and incorrect sentences, and incorrect use of spelling. He argued that these problems might be due to the interference of the mother-tongue, lack of vocabulary items and cultural differences in terms of concepts and values. Very recently, Khoshafah (2008) confirmed those findings of Moharram (2004) when he analyzed six business documents translated by 20 Yemeni translators .

Ahmed Maher and Mahmoud Al-Nakhalah (2011) conducted a study about the difficulties and problems faced by English Language and Literature students at Al Quds Open University when translating legal documents from Arabic to English and from English to Arabic. The test was applied on English Language students of Al Quds Open University in Gaza Region in Palestine during the second course of the academic year 2010/2011. The samples of the study were chosen and selected randomly. The findings of the research indicated that translator students face difficulties in finding an appropriate equivalents and lack of vocabulary.

Al-Darawish (1983) stated that four main difficulties in any translation face most of the translators of English as a foreign language. This includes 1). no two languages have exactly identical phonological, morphological, lexical, syntactic and semantic features, 2). languages differ in terms of sentence arrangement, 3). a translator is forced to front or move backward certain items, and 4). the impossibility for a translator to completely master two. Similarly with ElZeini (1994) he classified the problems of translation to six main problems in translating from Arabic to English and vice versa: lexicon, morphology, syntax textual differences, rhetorical differences, and pragmatic problems.

Masoud Mahmoodzadeh and Sheikhbahaee (2012) conducted a study to investigate the errors made by Iranian EFL learners at University Isfahan, Iran. The translation task aimed at identifying the interlingual preposition errors caused by the process of transfer between the target language (English) and the source language (Persian).their sample consists of 53 adults EFL learners at intermediate level. The results of study indicated that Iranian EFL learners faced errors related to the wrong and redundant use of prepositions. More frequently as compared with errors related to omission of prepositions in second language while translating from Persian into English.

\section{Methods}

In order to achieve appropriate data elicitation, the researcher selected 15 postgraduate abstracts for students who have finished their M.A in Evaluation and Measurement at Mu'tah University in Jordan for the academic year 2014. The sample of the study was selected randomly. The research used two research instruments including textual analysis of the selected abstracts and semi-structured interviews that comprised 13 items targeting the translators' opinions and views about the process of translating words' categories in the field of evaluation and measurement. Then, the researcher classified words in the abstracts and analyzed them each according to its category and tabulated them in a special format for discussion. On the other hand, he analyzed the interviews by looking at themes that emerge. The interviews were conducted by three translators. 


\section{Discussion of the Findings}

Based on analysis of the data, the findings indicate that translators faced different problems in translation. This included problems that relate to word categories such as adjectives, adverbs, verbs, nouns, pronoun, phrasal verbs and prepositions. Table (1) displays the frequencies of the errors made by the three translators according to the word category.

Table 1. The Frequencies of Translation Errors Made by the Translators According to Words' Categories

\begin{tabular}{lccccc}
\hline \multicolumn{1}{c}{ Statement } & $\begin{array}{c}\text { Translator } \\
(\mathrm{T} 1)\end{array}$ & $\begin{array}{c}\text { Translator } \\
\text { (T2) }\end{array}$ & $\begin{array}{c}\text { Translator } \\
\text { (T3) }\end{array}$ & Frequency & Percentage \\
\hline $\begin{array}{l}\text { 1.Using prepositions in } \\
\text { exact place. }\end{array}$ & 4 & 4 & 2 & 10 & 66.6 \\
$\begin{array}{l}\text { 2. It is difficult to know that, } \\
\text { Adjectives describe }\end{array}$ & 4 & 2 & 2 & 8 & 53.28 \\
$\begin{array}{l}\text { nouns. } \\
\text { 3.It is difficult to know that, } \\
\quad \text { Adverbs describe verbs. }\end{array}$ & 1 & 2 & 3 & 6 & 39.96 \\
$\begin{array}{l}\text { 4.The right arrangement of } \\
\text { Adjectives. }\end{array}$ & 2 & 3 & 0 & 5 & 33.3 \\
$\begin{array}{l}\text { 5.Verbs don't accept "ING". } \\
\text { 6.Problems in using phrasal } \\
\quad \text { verbs. }\end{array}$ & 1 & 2 & 1 & 4 & 26.64 \\
$\begin{array}{l}\text { 7.The use of modals in their } \\
\text { meaning. }\end{array}$ & 5 & 3 & 3 & 9 & 59.94 \\
\hline 8. The use of pronouns. & 1 & 0 & 1 & 7 & 46.62 \\
\hline
\end{tabular}

As displayed in Table (1) above the percentage of committing and error using preposition in the exact place recorded $66.6 \%$ in which T1 reported 4errors, T2 revealed 4 errors and T3 reported 2 errors. When asked to state that it is difficult to know that adjectives describe nouns, T1 showed 4 errors,T2 indicated 2 errors and T3 recorded 2 errors demonstrating 53,28 \% of the responses. Similarly, T1 showed 1 errors, T2 presented 2 errors and T3 recorded 3 errors when asked about the difficulty to know that adverbs describe verbs demonstrating 39.96\%. Likewise, translators revealed that the arrangement of adjectives within a sentence in English language causes them problems when translating M.A abstracts in which T1 recorded 2 errors, T2 showed 3 errors and T3 pointed 0 errors recording 33.3\%. Also, verbs that do not accept " ING" appeared to be very problematic for translators, T1 for example committed 1 error, T2 indicated 2 errors and T3 presented 1 error making $26.64 \%$ of the overall responses. When working with translation, translators find the use of phrasal verbs very significant and problematic, T1 reported 3 errors, T2 recorded 3 errors and T3 showed 3 errors demonstrating 59.94\%. On the other hand, the findings of the research indicated that T1 made 5 errors, T2 showed 1 error and T3 revealed 1 error when translating modals and their meaning recording a percentage of $46.62 \%$. Finally, the three translators showed that there are some difficulties that relate to the use of pronouns in both languages, T1 showed 1 error, T2 reported no errors and T3 recorded no errors as well making 6.66\% percentage out of the overall the responses frequencies as displayed in Figure (1) below.

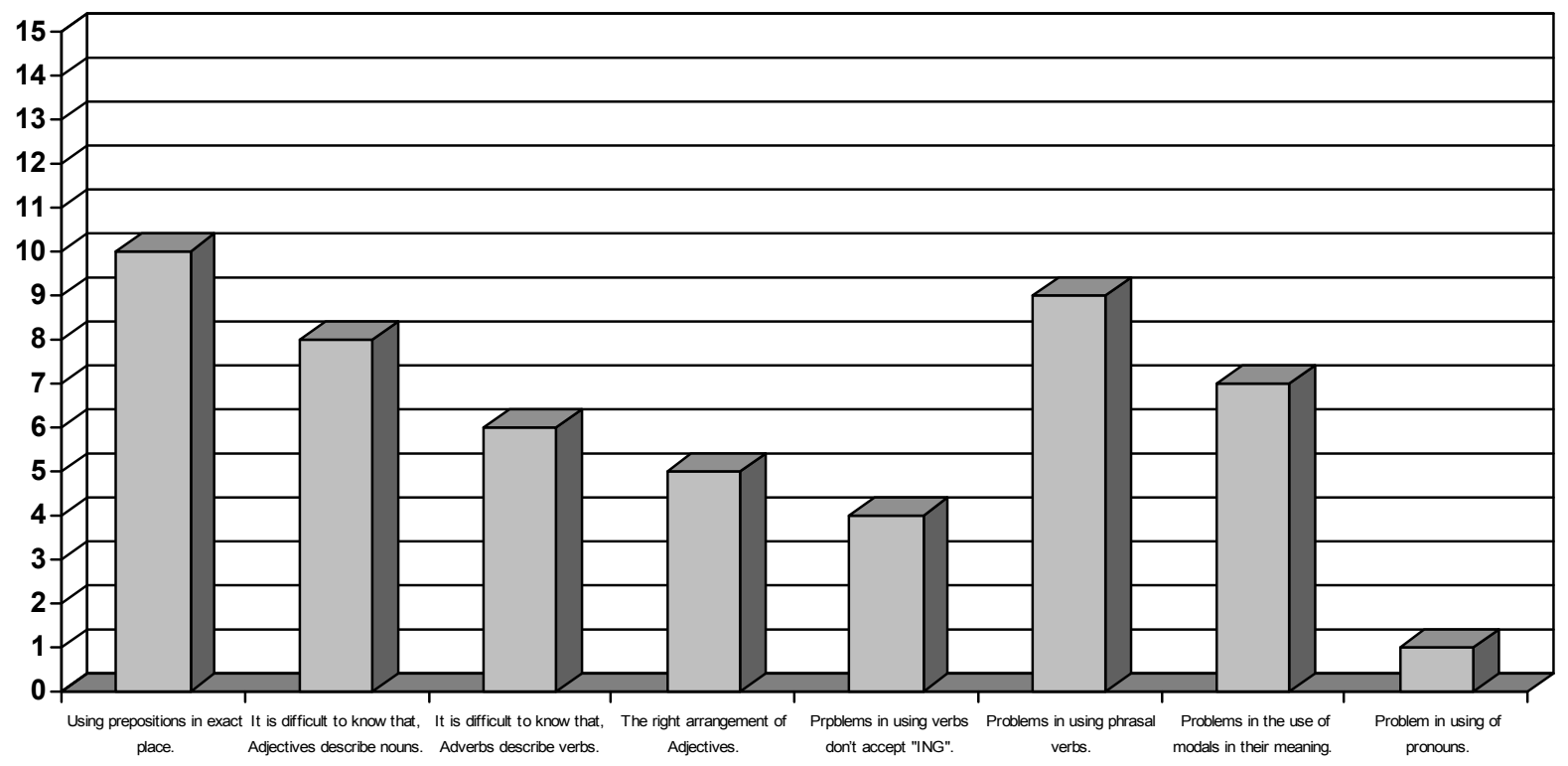

Figure 1. The Frequencies of Translation Errors Made by the Translators According 
In conclusion, based on the discussion of the findings of the research, one may demonstrate that words' categories are very problematic and confusing when translating fro English language into Arabic language or from Arabic into English language. That is all the three translators agree that the use of categories including nouns, pronouns, verbs, phrasal verbs, modals and prepositions. The translators demonstrated that the most difficult problem in translating M.A abstracts in Evaluation and Measurement is the use of prepositions in the right place and the know-how of using adjective to describe nouns in both language where WO (word order) matters in the process of translation.

\section{Conclusion}

In this study, the researcher has investigated the major challenges that face Jordanian EFL translators when translating postgraduate student abstracts from Arabic into English and vice versa. The qualitative and quantitative analyses helped in classifying those issues which several translators face while translating from SL to TL. The results show that there is a significant relationship between words categories and translation ability. Translators agree that the use of categories including nouns, pronouns, verbs, phrasal verbs, modals and prepositions. The translators demonstrated that the most difficult problem in translating M.A abstracts in Evaluation and Measurement is the use of prepositions in the right place and the know-how of using adjective to describe nouns in both language where WO (word order) matters in the process of translation.

\section{References}

Bell, X. (1991). Translation and Translating: Theory and Practice Longman, Applied Linguistics and Language Study General Editor: Christopher N. Candlin published by Longman Group UK.

Baker, M. (1992). In the Other Words. ( A Course book on Translation). $2^{\text {nd }}$ ed. London and New York. published in the USA and Canada by Routledge.

Miller, G. A, and Charles, W. G (1991). Contextual correlates of semantic similarity. Language and Cognitive Processes. Communication of the ACM, 38(11), 39-41.

Al Sohbani and Muthanna (2012). Challenges of Arabic -English Translation. International Journal of English Linguistics, 2(6).

Sein, A.F. (2010). Translatability of Collocations: A Constant Challenge to EFL Learners. Jordan Journal of Educational Sciences, 7(2), 209-219.

Ahmed M, A. (2011). Al Quds Open University in Palestine The Difficulties and Problems Faced by the English Language Students of Al Quds Open University in Legal Translation Process. International Journal of English language and translational studies, 1(3),157-157.

Sheikhbahaee, M. (2012). Cross-linguistic Study of Prepositions in Persian and English: The Effect of Transfer. Theory and Practice in Language Studies, 2(4).

Anas, A.K.(2013). The Translation of Puns A Semantic or Pragmatic Equivalent, An-Najah National University, Nablus, Palestine 2013| This Thesis is Submitted in Partial Fulfillment of the Requirements of the Degree of Masters of Arts.

El Zeini, N.,T. (1994). Criteria for the Evaluation of Translation : A Pragma-stylistic approach. Translation Journal and the Authors 2002, 6(3).

Miller, G. A., and Fellbaum, C. (1992) Semantic networks of English. In B. Levin and ,S. Pinker Eds. Lexical and Conceptual Semantics. Blackwell, Cambridge and Oxford, England, 1992, pp. 197-229. COMMUNICATIONS OF THE ACM, 38(11).

Darawish ,H. (1983). Arabizing university education in Arabic Jerusalem, Arab studies society. Cited Hamdallah, R., Problems and approaches to translation with reference to Arabic. language and translation. J. king Saud University, pp 23-38 -1998. 